\title{
Brief communication: New radar constraints support presence of ice older than 1.5 Myr at Little Dome C
}

\author{
David A. Lilien ${ }^{1, \star}$, Daniel Steinhage ${ }^{2, \star}$, Drew Taylor ${ }^{3}$, Frédéric Parrenin ${ }^{4}$, Catherine Ritz ${ }^{4}$, Robert Mulvaney ${ }^{5}$, \\ Carlos Martín ${ }^{5}$, Jie-Bang Yan $^{3}$, Charles O’Neill ${ }^{3}$, Massimo Frezzotti ${ }^{6}$, Heinrich Miller ${ }^{2}$, Prasad Gogineni ${ }^{3}$, \\ Dorthe Dahl-Jensen ${ }^{1,7}$, and Olaf Eisen ${ }^{2,8}$ \\ ${ }^{1}$ Physics of Ice, Climate and Earth, Niels Bohr Institute, University of Copenhagen, Copenhagen, Denmark \\ ${ }^{2}$ Alfred-Wegener-Institut Helmholtz-Zentrum für Polar-und Meeresforschung, Bremerhaven, Germany \\ ${ }^{3}$ Remote Sensing Center, University of Alabama, Tuscaloosa, AL, USA \\ ${ }^{4}$ Institut des Géosciences de l'Environnement, University Grenoble Alpes, CNRS, IRD, IGE, Grenoble, France \\ ${ }^{5}$ British Antarctic Survey, Natural Environment Research Council, Cambridge, UK \\ ${ }^{6}$ Department of Science, University Roma Tre, Rome, Italy \\ ${ }^{7}$ Centre for Earth Observation Science, University of Manitoba, Winnipeg, MB, Canada \\ ${ }^{8}$ Department of Geosciences, University of Bremen, Bremen, Germany \\ ฟThese authors contributed equally to this work.
}

Correspondence: David A. Lilien (david.lilien@nbi.ku.dk)

Received: 23 November 2020 - Discussion started: 7 December 2020

Revised: 8 March 2021 - Accepted: 10 March 2021 - Published: 19 April 2021

\begin{abstract}
The area near Dome C, East Antarctica, is thought to be one of the most promising targets for recovering a continuous ice-core record spanning more than a million years. The European Beyond EPICA consortium has selected Little Dome C (LDC), an area $\sim 35 \mathrm{~km}$ southeast of Concordia Station, to attempt to recover such a record. Here, we present the results of the final ice-penetrating radar survey used to refine the exact drill site. These data were acquired during the 2019-2020 austral summer using a new, multi-channel highresolution very high frequency (VHF) radar operating in the frequency range of $170-230 \mathrm{MHz}$. This new instrument is able to detect reflectors in the near-basal region, where previous surveys were largely unable to detect horizons. The radar stratigraphy is used to transfer the timescale of the EPICA Dome C ice core (EDC) to the area of Little Dome C, using radar isochrones dating back past $600 \mathrm{ka}$. We use these data to derive the expected depth-age relationship through the ice column at the now-chosen drill site, termed BELDC (Beyond EPICA LDC). These new data indicate that the ice at BELDC is considerably older than that at EDC at the same depth and that there is about $375 \mathrm{~m}$ of ice older than $600 \mathrm{kyr}$ at BELDC. Stratigraphy is well preserved to $2565 \mathrm{~m}, \sim 93 \%$ of the ice thickness, below which there is a basal unit with unknown
\end{abstract}

properties. An ice-flow model tuned to the isochrones suggests ages likely reach $1.5 \mathrm{Myr}$ near $2500 \mathrm{~m}, \sim 65 \mathrm{~m}$ above the basal unit and $\sim 265 \mathrm{~m}$ above the bed, with sufficient resolution $\left(19 \pm 2 \mathrm{kyr} \mathrm{m}^{-1}\right)$ to resolve $41 \mathrm{kyr}$ glacial cycles.

\section{Introduction}

Ice cores provide one of the best records of paleoclimate on $100 \mathrm{kyr}$ timescales, but to date no continuous ice core has been recovered that spans more than $800 \mathrm{kyr}$ in stratigraphic order. There is great interest in extending ice-core records beyond the mid-Pleistocene transition ( 1.25 to $0.7 \mathrm{Ma})$, since this may provide unique insight in the mechanism which caused the switch between 41 and $100 \mathrm{kyr}$ ice-age cycles. An ice core spanning the last $\sim 1.5 \mathrm{Myr}$ would extend into the period characterized by regular $41 \mathrm{kyr}$ cycles and would provide a more precise record of greenhouse gases through this transition than is currently available (Fischer et al., 2013). Several nations or consortia of nations are endeavoring to recover such cores in East Antarctica as part of the International Partnerships in Ice Core Sciences (IPICS; Beyond EPICA near Dome C, Australia near Dome C, China near 
Dome A, Japan near Dome F, Russia near Ridge B, and the USA in the Allan Hills and exploring other potential sites; see other articles in this special issue for details on these efforts).

The EPICA Dome C ice core (EDC; EPICA Community Members, 2004), drilled at the location now occupied by Concordia Station in East Antarctica, provides the oldest stratigraphic ice-core climate record recovered to date. The site's cold conditions, low accumulation, and thickness are conducive to preserving old ice. However, slight melting at the bed suggests that a nearby site with slightly thinner ice, and thus no basal melt, could preserve a longer record. Ideally, that site would have relatively smooth bed topography to prevent flow-induced disturbances. Modeling identified two candidate targets in the area (Parrenin et al., 2017), and subsequent work (Passalacqua et al., 2018; Young et al., 2017) narrowed the search to an area $\sim 35 \mathrm{~km}$ southwest termed Little Dome C (LDC, Fig. 1). To obtain the oldest ice at maximum resolution, the core would ideally be at a location where the ice is as thick as possible without allowing basal melting. While the minimum ice thickness to allow melting varies spatially with accumulation, ice flow, and geothermal heat flux, several constraints are available for the region. Analysis of airborne radar data identified a number of subglacial lakes, all of which lie beneath at least $2875 \mathrm{~m}$ of ice (Young et al., 2017). Though not framed specifically in terms of minimum ice thickness to cause melting, several thermal modeling studies suggest that parts of LDC with ice thickness around $2700 \mathrm{~m}$ are likely free of basal melt (Passalacqua et al., 2018; Parrenin et al., 2017; Van Liefferinge et al., 2018).

Extensive radar work has been conducted in the area of LDC in the framework of Beyond EPICA, which greatly narrowed the area this present work examined. The initial aerial survey (Young et al., 2017) mapped the bedrock extensively, greatly improving the knowledge of the bed compared to the single Operation IceBridge flight line in the area. These results also allowed further inference of basal conditions (Passalacqua et al., 2017; Van Liefferinge et al., 2018) as well as the accumulation rate in the area over the last 73 kyr (Cavitte et al., 2018). Those results led to a targeted ground-based survey using an impulse radar operating in the 1-5 MHz range (Cavitte et al., 2020), which narrowed the core location to an $\sim 8 \mathrm{~km}^{2}$ area. While modeling shows that LDC is likely to have old ice (e.g., Van Liefferinge and Pattyn, 2013), those previous radar surveys were not able to connect any isochrones older than $\sim 400 \mathrm{kyr}$ throughout the area to the EDC ice core, leaving large uncertainties in the ages nearer the bed. This inability to trace older horizons stems from a near-basal region that is common in Antarctica, previously described as the "echo-free zone". The cause of the echo-free zone is unclear and has been variously attributed to a sharp thermal transition, folding or buckling, and recirculation and re-crystallization (see Drews et al., 2009, for a detailed discussion). Indeed, the existence of an echo-free

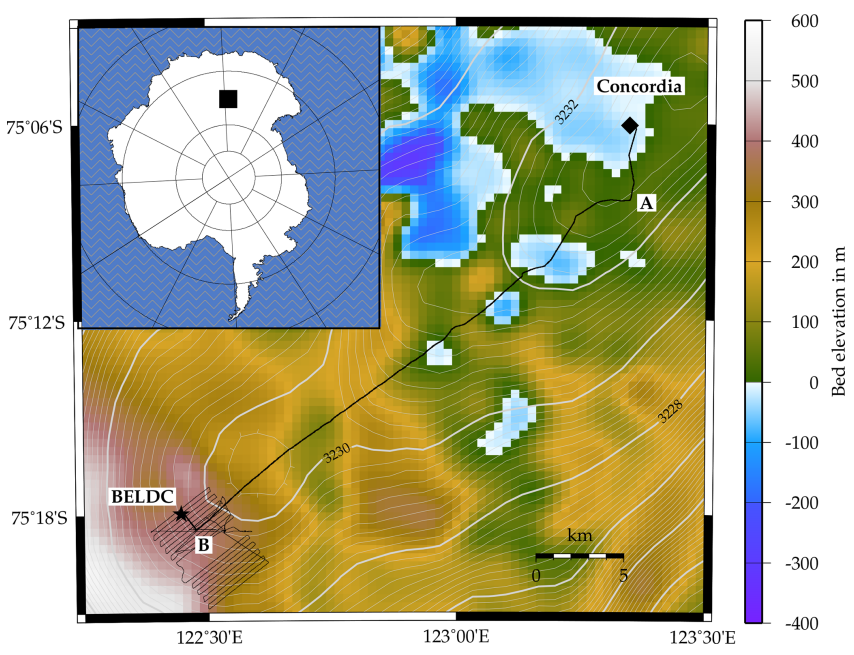

Figure 1. Map of study area, with inset showing location in Antarctica. Black lines show radar profiles acquired in 2019, with bold line showing the profile evaluated here. EDC core coincides with Concordia. Contours show surface elevation from Helm et al. (2014). Background colors are bed elevation relative to sea level from BedMachine Antarctica v2 (Morlighem et al., 2020).

zone is disputed, as it may simply be an artifact of radarsystem detection limits. Regardless of the cause, the lack of reflections near the bed in prior surveys of LDC limited constraints on very old ice in the region. In addition to the echofree zone, some radargrams showed a diffuse horizon near the bed, hinting that basal ice in the area may have different physical properties than the overlying ice (Cavitte, 2017), though the implications for the depth relationship were unclear.

Here, we present the results of an additional radar survey designed to connect the stratigraphy of that site with the EDC core and to identify the area at LDC with the highest potential for old ice. This survey utilized a new, highly sensitive radar, which allowed for detection of older horizons nearer the bed. The exact location for the ice core, Beyond EPICA LDC (BELDC; $75.29917^{\circ} \mathrm{S}, 122.4451^{\circ} \mathrm{E} ; 3230 \mathrm{~m}$ above the WGS84 ellipsoid as of 2020), has deep, flat, visible stratigraphy and lies within the region of LDC identified by previous studies to be free of melt and likely to contain old ice. Here, we present the age constraints provided by this new radar survey for that chosen site by comparing the stratigraphy to EDC.

\section{Methods}

\subsection{Data collection and processing}

Data were collected using a new very high frequency (VHF) radar, built by the Remote Sensing Center at the University of Alabama (Yan et al., 2020). The system was configured to transmit $8 \mu$ s chirps, with $200 \mathrm{MHz}$ center frequency and 
$60 \mathrm{MHz}$ bandwidth. Peak transmit power was varied from $125-250 \mathrm{~W}$ through the campaign to maximize the signalto-noise ratio while limiting problems with radio-frequency interference. The system has eight transmit and receive channels, paired with eight monostatic antennas. Due to the logistical challenges of the operating environment, the number of channels in use varied from five to eight. The system was pulled behind a tracked vehicle, with controlling electronics in the rear passenger compartment and antennas approximately $12 \mathrm{~m}$ behind. The antennas were set up such that the electric field polarization was oriented across track, above a single sheet of plywood for stiffness and thin PVC mat for slipperiness. Data were collected at travel speeds of 2$3.5 \mathrm{~m} \mathrm{~s}^{-1}$ over the course of a week in November and December 2019.

Data processing consisted of coherent integration (i.e., unfocused SAR), pulse compression, motion compensation (by tracking internal horizons), coherent channel combination, and de-speckling using a median filter. Two-way travel time was converted to depth assuming a correction of $10 \mathrm{~m}$ of firn air and a constant radar wave speed in ice of $168.5 \mathrm{~m} \mathrm{us}^{-1}$ (e.g., Winter et al., 2017). After other processing was complete, different radargrams were spliced together to create a continuous profile extending from EDC to BELDC, and then the data were interpolated to have constant $10 \mathrm{~m}$ horizontal spacing. The re-interpolated data were used for horizon tracing, which was done semi-automatically to follow amplitude peaks between user-defined clicks. For the bed reflection, there were often weak, diffuse events shallower than a clear return. We always picked the first notable return in the region of the bed, so ice-thickness estimates are likely biased shallow; the number of hyperbolic and diffuse events, likely originating from roughness of the ice-bed interface or physical changes in the lower parts of the ice sheet, would cause a high risk of misinterpretation with other approaches.

\subsection{Horizon dating and depth-age reconstruction}

Radar reflectors were dated by interpolating from the AICC2012 timescale (Bazin et al., 2013) at the point of closest approach to the EDC drill site. The radar line ended approximately $100 \mathrm{~m}$ horizontally from the EDC borehole. The depth of the bed reflection there is $3238 \mathrm{~m}(38.32 \mu \mathrm{s})$, within the depths at closest approach to EDC found by other radar systems (approximately 3220-3286 $\mathrm{m}$ in Winter et al., 2017) but shallower than the minimum actual thickness implied by the $3260 \mathrm{~m}$ EDC borehole (Parrenin et al., 2007). This offset is likely due to some combination of off-nadir reflection, debris in the ice, small differences in topography over the $100 \mathrm{~m}$ offset, and uncertainty in firn-air content and wave speed. Regardless of the cause, we must either re-scale the thickness to match EDC or leave it as measured. We choose the latter since any re-scaling would be highly uncertain.

The dating uncertainty has two primary components: uncertainty in the ice-core timescale and uncertainty in the radar-horizon depth. The horizon-depth uncertainty can be further subdivided into the component caused by the radargram not extending exactly to the EDC core site and the component caused by the firn correction and dielectric constant (see Winter et al., 2017, and references therein for a detailed discussion of the components of the error). For the ice-core uncertainty, we use the previously published estimates from the chronology (Bazin et al., 2013). We estimated slope-induced uncertainty from the $\sim 100 \mathrm{~m}$ offset of the radargram from the core using each horizon's average slope; slopes ranged from 10 to $60 \mathrm{~m} \mathrm{~km}^{-1}$, resulting in depth uncertainty of 1 to $6 \mathrm{~m}$, increasing with depth. The depth uncertainty introduced by anisotropy and temperature affecting the dielectric constant is taken to be $1 \%$, and we assume an additional $3 \mathrm{~m}$ uncertainty in the firn-air correction. The formal quarter-wavelength uncertainty of the horizon position is small $(0.2 \mathrm{~m})$ compared to other terms. Thus, total depth uncertainties range from $11 \mathrm{~m}$ for the upper horizons to $31 \mathrm{~m}$ for the lower horizons, introducing age uncertainties of 1 to $33 \mathrm{kyr}$ (found using the depth gradient of age following Winter et al., 2017). Combining with uncertainties in the timescale itself, total age uncertainties increase from $2 \mathrm{kyr}$ for shallow horizons to $34 \mathrm{kyr}$ for the deepest ones. The uncertainties of the horizons' ages are correlated with each other, since an incorrect firn-air correction or dielectric constant, or an incorrect age scale at EDC, affects the inferred age of all these horizons, though we are unable to quantify the extent of this correlation.

\subsection{Modeling the depth-age scale}

While previous work has used sophisticated models to make estimates of the depth-age scale at LDC (Parrenin et al., 2017), here we seek a more simple constraint relying on the tighter age bounds of the new radar data. We fit a modified Lliboutry model (Lliboutry, 1979) to the horizons at the chosen core site. The model provides an analytic solution for the vertical thinning function, $\lambda(d)$, where $d$ is depth, the inverse of which can be integrated to find the steady-state age, $\bar{t}$, at a given depth. That is,

$\bar{t}(d)=\int_{0}^{d} \frac{1}{\lambda\left(d^{\prime}\right)} \mathrm{d} d^{\prime}$.

Assuming no basal melt or accretion, and ignoring firn, the Lliboutry model approximates layer thickness as

$\lambda(d)=a\left(1-\frac{p+2}{p+1}\left(\frac{d}{H}\right)+\frac{1}{p+1}\left(\frac{d}{H}\right)^{p+2}\right)$,

where $a$ is ice-equivalent accumulation, $H$ ice thickness, and $p$ a shape factor controlling the vertical profile of deformation.

As in Parrenin et al. (2017), we used a temporally variable accumulation rate and solved for the depth-age relationship 
using a pseudo-steady method which permits analytical solutions for $\lambda$ even with temporally variable accumulation (Parrenin et al., 2006). This involves a simple change of variable between time, $t$, and steady time, $\bar{t}$, of the form

$\bar{t}=\int_{0}^{t} R\left(t^{\prime}\right) \mathrm{d} t^{\prime}$,

where $R(t)=a_{\mathrm{E}}(t) / \bar{a}_{\mathrm{E}}$ is the normalized accumulation at a given time of the EDC record (Bazin et al., 2013), and we assume $R=1$ for ages older than the extent of the EDC record. Equation (3) defines a bijection between $t$ and $\bar{t}$, so we can first find the steady-state age profile using Eq. (1) and then convert to the equivalent profile incorporating the EDC accumulation variations using Eq. (3). In this formulation, the temporally variable accumulation enters only as the nondimensional scaling, $R(t)$, while $a$ in Eqs. (1)-(2) is treated as a constant.

We used a Markov chain Monte Carlo method, implemented with PyMC3 (Salvatier et al., 2016), to find the probability distribution of the resulting depth-age scale by varying $a, H$, and $p$. We allowed $H$ to vary to account for the possibility of stagnant ice which does not affect the deformation of the overlying ice column. Aside from the minor difference of using a newer Monte Carlo sampler and fitting for the effective thickness, $H$, the essential difference between this model and that used by Parrenin et al. (2017) is that we have excluded the possibility of basal melt and thus all thermal modeling; this is justified by the previous thermal modeling in the area (Passalacqua et al., 2018; Parrenin et al., 2017; Van Liefferinge et al., 2018) as well as radar evidence from other surveys (Young et al., 2017). This model strikes a balance between numerical requirements and a realistic, singularity-free profile of strain at different depths (Parrenin et al., 2006).

\section{Results}

The processed radargram shows a clear bed reflection and a number of horizons that can be continuously traced from EDC to LDC (Fig. 2). The data indicate that the thickness at the chosen site at LDC is $2764 \pm 20 \mathrm{~m}$, with the top $2565 \pm 20 \mathrm{~m}$ showing continuous stratigraphy. Around $2565 \mathrm{~m}$ there is a change in the amplitude of the radar returns that suggests ice below this depth has different properties; this feature is discussed further in Sect. 4.1. The ice thickness is $>100 \mathrm{~m}$ less than the minimum thickness over any subglacial lake observed in the area (Young et al., 2017), and there is no non-bed-parallel down-warping of englacial horizons, both indicating that the site is free of basal melt. To the east of LDC (near kilometer 14 and 27 in Fig. 2) there is some down-warping of englacial horizons, but the ice in that area is thicker than at BELDC as the bed deepens in subglacial valleys.
We traced a subset of the visible horizons, selected to span all depths with a concentration in the deepest areas. In addition to the continuous horizons, there were three deep horizons that could be identified near both ends of the radargram, where horizon slopes are relatively flat, but not in the middle of the radargram, where horizon slopes were steeper. We also traced these three partial horizons where possible, to attempt a more complete connection of the core's timescale to the BELDC site. Despite the gaps in the middle of the profile, the relatively distinctive pattern of these horizons gives us confidence that they are the same isochrone at each end of the profile (see Fig. 2b-e for zoom-ins on these horizons). However, since it is possible that we have misidentified these horizons, the depth-age analysis in Sect. 4.2 is repeated with the three deepest horizons excluded.

At the intersection with EDC, horizons were dated from 71 to $565 \mathrm{ka} \mathrm{(Fig.} \mathrm{2).} \mathrm{Of} \mathrm{these,} \mathrm{four} \mathrm{isochrones} \mathrm{were} \mathrm{older} \mathrm{than}$ $399 \mathrm{kyr}$, the age of the oldest previously isochrone previously dated and traced from EDC (Parrenin et al., 2017). The oldest isochrone that could be continuously traced to BELDC was dated to $465 \mathrm{ka}$. This increase in the age of dated isochrones introduces a significantly tighter constraint upon the age and age resolution at the LDC site than was previously available. These data indicate that ice reaches $600 \mathrm{kyr}$ at a relatively shallow $2373 \pm 20 \mathrm{~m}$ at the chosen BELDC site. The older radar ages lead us to infer ice older than $1.5 \mathrm{Myr}$, with $\sim 19 \mathrm{kyr} \mathrm{m}^{-1}$ resolution as detailed in Sect. 4.2.

\section{Discussion}

We first discuss a thick basal unit at LDC that may affect the depth-age relationship, before focusing on the depth-age distribution at the BELDC site.

\subsection{Basal unit}

At LDC, there is a notable event (i.e., change in the return power) in the radargram around $2565 \mathrm{~m}$ depth (pink line in Fig. 2). While there are some distinct peaks in return power that arrive later than this event, and thus most likely originate deeper, there are no continuous or coherent reflecting horizons below this depth. However, this event is at a depth where the radar is capable of imaging continuous reflections throughout most of the radar profiles, suggesting a change in ice properties rather than a system detection limit. Other radars noted a diffuse event at this depth (Cavitte, 2017), but the additional sensitivity of this new survey helps establish that the origin of the event is in fact a physical property of the ice and not an artifact. It may be caused by a sharp transition in crystal fabric, heterogeneous small-scale roughness, stagnant ice, tightly spaced or disrupted isochrones, or perhaps some other relic feature; regardless of its origin, the lack of stratigraphy suggests that recovery of a climate record below this depth may be difficult, potentially impossible. How- 


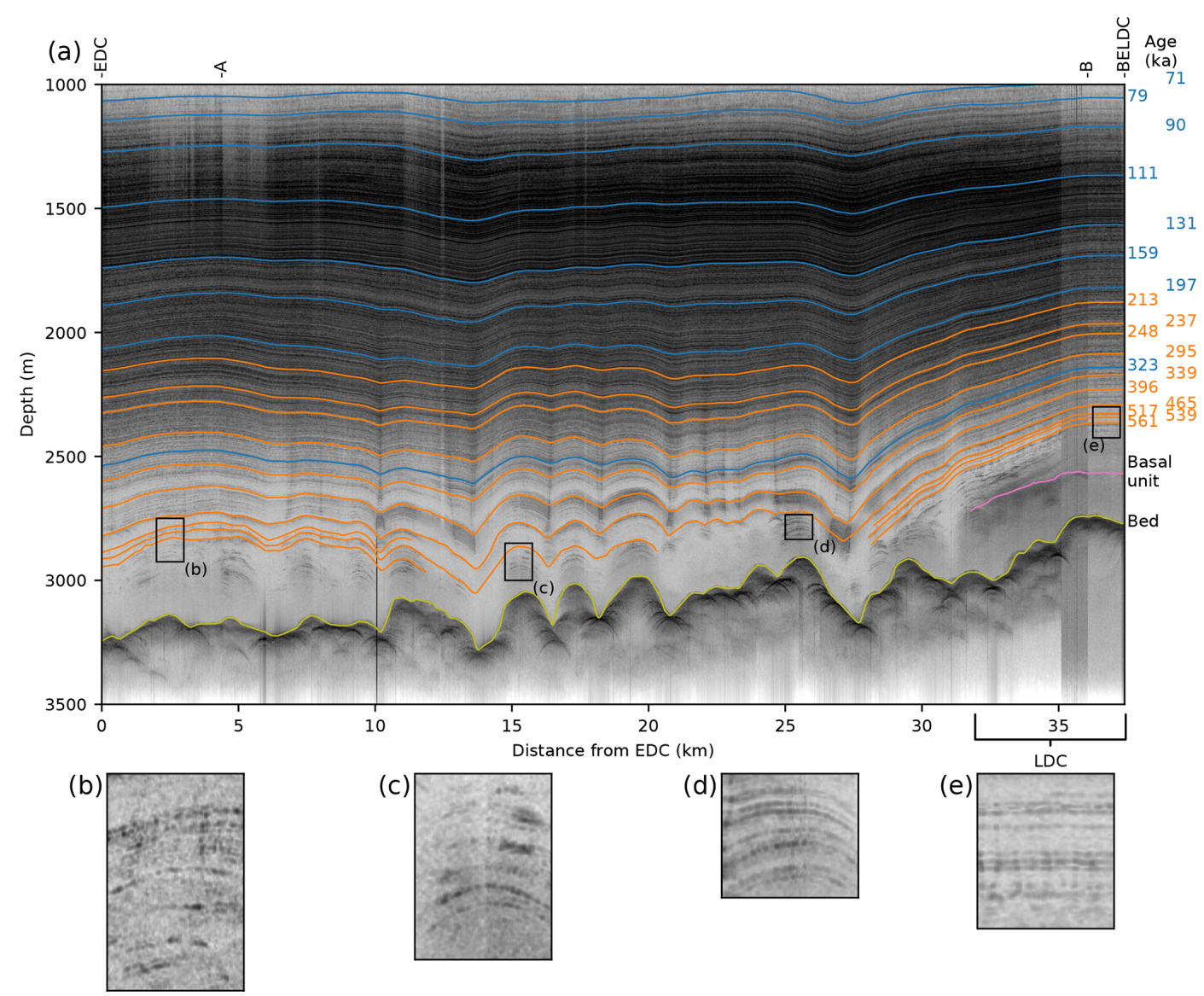

Figure 2. (a) Radargram extending from EDC to the chosen ice-core site, BELDC. Blue and orange lines show horizons traced by Winter et al. (2017) and newly traced here, respectively, with ages on the right. Marks at the top show turns in the profile, as noted on Fig. 1. (b-e) Zoom-ins of discontinuous horizons at locations in panel (a).

ever, despite the lack of continuous radar isochrones, studies at other ice-core sites (e.g., EDC and EDML) showed that climate information might still be retrievable at least in the top part of basal units with similar characteristics (e.g., Tison et al., 2015).

\subsection{Depth-age scale at the BELDC site}

The depth-age scale from a random sample of parameters drawn from the posterior distributions of $a, H$, and $p$ is shown by the gray bands in Fig. 3b. The green bars show the results with only continuous horizons used to constrain the model. The $95 \%$ confidence interval with the discontinuous horizons included is a subset of the $95 \%$ confidence interval using continuous horizons only; including discontinuous horizons narrows the distribution to be slightly younger and to have slightly higher depth-age resolution. For the rest of this section, stated values include the discontinuous horizons as a constraint, while parentheticals use continuous horizons only. Uncertainties in this section are the standard deviation of the distribution of modeled depth-age profiles.
The best-fit ice thickness is $2579 \pm 22 \mathrm{~m}(2549 \pm 32 \mathrm{~m})$, within uncertainty of the top of the basal unit. The mean accumulation is $14.5 \pm 0.2 \mathrm{~kg} \mathrm{~m}^{-2} \mathrm{a}^{-1}$ $\left(14.4 \pm 0.2 \mathrm{~kg} \mathrm{~m}^{-2} \mathrm{a}^{-1}\right)$, close to the $13.9 \mathrm{~kg} \mathrm{~m}^{-2} \mathrm{a}^{-1}$ average found in the EDC core (Bazin et al., 2013). The shape factor is $5.5 \pm 1(6.5 \pm 1.5)$. The relatively small effective ice thickness suggests that the basal unit is partially stagnant or flows much more slowly than the overlying ice, such that the deformation of the overlying ice column is unaffected by this deeper ice and ages reach an asymptote near the top the basal unit. The corresponding depth-age scales reach $1.5 \mathrm{Myr}$ at $2498 \pm 14 \mathrm{~m}(2476 \pm 25 \mathrm{~m})$, with average age resolution of $19 \pm 2 \mathrm{kyr} \mathrm{m}^{-1}\left(21 \pm 3 \mathrm{kyr} \mathrm{m}^{-1}\right)$. Including the discontinuous horizons in the age modeling thus suggests that resolution is sufficient for measuring $41 \mathrm{kyr}$ glacial cycles at this age, while using continuous horizons only suggests that the resolution may be marginal at $1.5 \mathrm{Myr}$. The original Beyond EPICA resolution target, $20 \mathrm{kyr} \mathrm{m}^{-1}$ (Fischer et al., 2013), is passed at age $1552 \pm 83 \mathrm{kyr}(1468 \pm 101 \mathrm{kyr})$. Regardless of whether discontinuous horizons are used, our modeling suggests that 


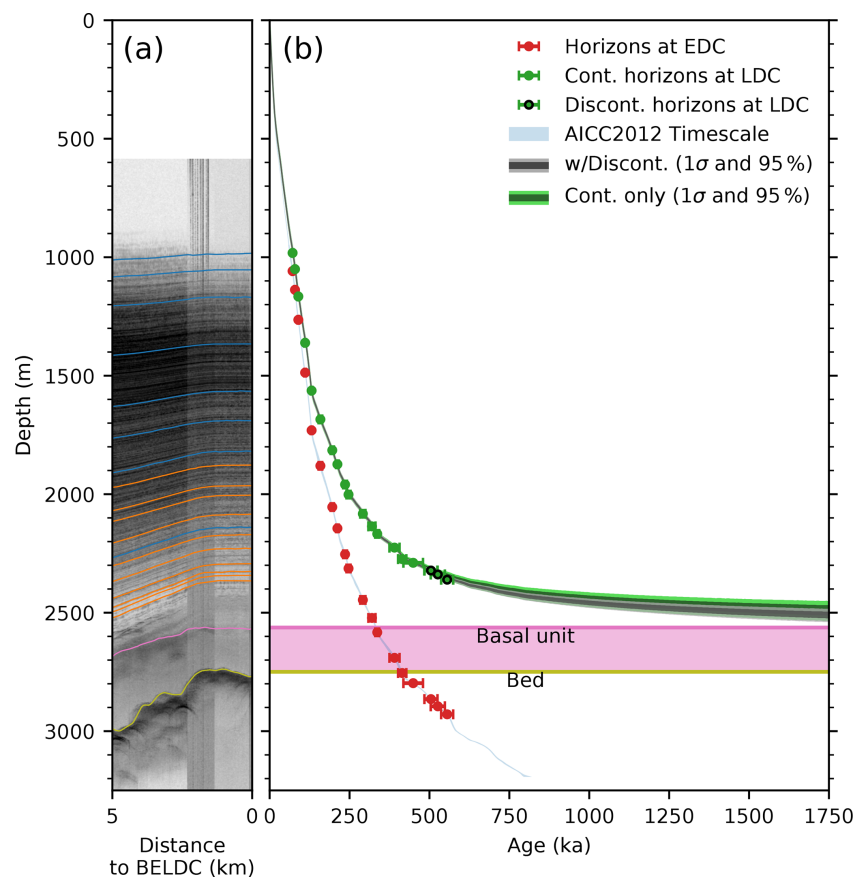

Figure 3. (a) Radargram near BELDC (as in Fig. 2). (b) Depth-age scale at BELDC and EDC. Dots with error bars show traced horizons with age uncertainties; blue line shows AICC2012 chronology (Bazin et al., 2013). The gray shaded regions show model results utilizing constraints from all horizons at $95 \%$ confidence (light) and $1 \sigma$ (dark). Green shaded region shows the model results with the discontinuous horizons excluded from the analysis.

conditions are close to the desired depth-age properties, though the deepest isochrones add confidence that the site fully meets the age and resolution targets. Further refinement of the depth-age scale with more sophisticated models and elaborate assumptions could refine the estimated age and age resolution but will likely result in broadly similar values.

\section{Conclusions}

Newly collected radar data provide a tighter constraint on the depth-age scale at LDC. These data reveal traceable stratigraphy in ice $>500 \mathrm{kyr}$ old in the region, with continuous horizons to $465 \mathrm{kyr}$. Near LDC, they also indicate a unit of basal ice in which few events are visible; the origin of this basal unit requires further investigations as its flow properties and composition are unknown. The stratigraphy indicates that old ice lies much shallower at BELDC than at EDC. A Lliboutry model of the depth-age scale, fitted to the isochrone data, indicates that $1.5 \mathrm{Myr}$ old ice lies at $\sim 2500 \mathrm{~m}$ depth, where stratigraphy is still intact and preserved with $\sim 19 \mathrm{kyr} \mathrm{m}^{-1}$ resolution. Very old ( $>1.5 \mathrm{Myr}$ ) ice could exist atop the basal unit, which appears partially stagnant and presumably also contains $>1.5 \mathrm{Myr}$ old ice, though the lack of stratigraphy does not allow firm conclusions regarding the extent to which useful climatic information may or may not be preserved below $2565 \mathrm{~m}$ depth.

Data availability. The radar profile displayed in Fig. 2 are archived at https://doi.org/10.5281/zenodo.4687049.

Author contributions. All authors contributed to survey design. PG, JBY, and CO designed and built the radar system. PG and JBY led the development of the processor. DS, DT, and DAL collected the radar data. DAL processed and traced the radar data and implemented the depth-age model. FP, CR, DDJ, OE, and DS also contributed to the age modeling. DAL and DS wrote the first draft of the manuscript. All authors contributed to writing the final manuscript.

Competing interests. Olaf Eisen is co-editor-in-chief and Carlos Martín is an editor of TC. The authors declare no other competing interests.

Special issue statement. This article is part of the special issue "Oldest Ice: finding and interpreting climate proxies in ice older than 700000 years (TC/CP/ESSD inter-journal SI)". It is not associated with a conference.

Acknowledgements. This publication was generated in the framework of Beyond EPICA. The project has received funding from the European Union's Horizon 2020 research and innovation program under grant agreement no. 815384 (Oldest Ice Core). It is supported by national partners and funding agencies in Belgium, Denmark, France, Germany, Italy, Norway, Sweden, Switzerland, the Netherlands, and the United Kingdom. Logistical support is mainly provided by PNRA and IPEV through the Concordia Station system. The radar shipment and personnel transportation to Antarctica were provided by the US NSF under grant 1921418, which also partly supported the development of the VHF radar. Radar development was further supported by internal funding from the University of Alabama. David A. Lilien and Dorthe Dahl-Jensen were partially supported by the Villum Foundation (grant number 16572). The opinions expressed and arguments employed herein do not necessarily reflect the official views of the European Union funding agency or other national funding bodies. This is Beyond EPICA publication number 13. We thank Saverio Panichi and Michele Scalet, as well as the Concordia Station team, for support in the field. We also thank the US National Guard and Royal New Zealand Air Force for the flights between Christchurch and McMurdo. We are grateful also for the logistical support from McMurdo and Zucchelli stations. We are thankful for the thoughtful comments from reviewers Lucas Beem and Xianbin Cui, from Marie Cavitte, and from editor Joe MacGregor, which improved the manuscript.

Financial support. This research has been supported by the Horizon 2020 (Beyond EPICA (grant no. 815384)), the National Science 
Foundation (grant no. 1921418), and the Villum Foundation (grant no. 16572).

Review statement. This paper was edited by Joseph MacGregor and reviewed by Lucas Beem and Xiangbin Cui.

\section{References}

Bazin, L., Landais, A., Lemieux-Dudon, B., Toyé Mahamadou Kele, H., Veres, D., Parrenin, F., Martinerie, P., Ritz, C., Capron, E., Lipenkov, V., Loutre, M.-F., Raynaud, D., Vinther, B., Svensson, A., Rasmussen, S. O., Severi, M., Blunier, T., Leuenberger, M., Fischer, H., Masson-Delmotte, V., Chappellaz, J., and Wolff, E.: An optimized multi-proxy, multi-site Antarctic ice and gas orbital chronology (AICC2012): 120-800 ka, Clim. Past, 9, 17151731, https://doi.org/10.5194/cp-9-1715-2013, 2013.

Cavitte, M. G. P.: Flow re-organization of the East Antarctic ice sheet across glacial cycles, Thesis, University of Texas, https://doi.org/10.15781/T2TT4G891, 2017.

Cavitte, M. G. P., Parrenin, F., Ritz, C., Young, D. A., Van Liefferinge, B., Blankenship, D. D., Frezzotti, M., and Roberts, J. L.: Accumulation patterns around Dome C, East Antarctica, in the last $73 \mathrm{kyr}$, The Cryosphere, 12, 1401-1414, https://doi.org/10.5194/tc-12-1401-2018, 2018.

Cavitte, M. G. P., Young, D. A., Mulvaney, R., Ritz, C., Greenbaum, J. S., Ng, G., Kempf, S. D., Quartini, E., Muldoon, G. R., Paden, J., Frezzotti, M., Roberts, J. L., Tozer, C. R., Schroeder, D. M., and Blankenship, D. D.: A detailed radiostratigraphic data set for the central East Antarctic Plateau spanning the last half million years, Earth Syst. Sci. Data Discuss. [preprint], https://doi.org/10.5194/essd-2020-393, in review, 2020.

Drews, R., Eisen, O., Weikusat, I., Kipfstuhl, S., Lambrecht, A., Steinhage, D., Wilhelms, F., and Miller, H.: Layer disturbances and the radio-echo free zone in ice sheets, The Cryosphere, 3, 195-203, https://doi.org/10.5194/tc-3-195-2009, 2009.

EPICA Community Members: Eight glacial cycles from an Antarctic ice core, Nature, 429, 623-628, https://doi.org/10.1038/nature02599, 2004.

Fischer, H., Severinghaus, J., Brook, E., Wolff, E., Albert, M., Alemany, O., Arthern, R., Bentley, C., Blankenship, D., Chappellaz, J., Creyts, T., Dahl-Jensen, D., Dinn, M., Frezzotti, M., Fujita, S., Gallee, H., Hindmarsh, R., Hudspeth, D., Jugie, G., Kawamura, K., Lipenkov, V., Miller, H., Mulvaney, R., Parrenin, F., Pattyn, F., Ritz, C., Schwander, J., Steinhage, D., van Ommen, T., and Wilhelms, F.: Where to find 1.5 million yr old ice for the IPICS "Oldest-Ice" ice core, Clim. Past, 9, 2489-2505, https://doi.org/10.5194/cp-9-2489-2013, 2013.

Helm, V., Humbert, A., and Miller, H.: Elevation and elevation change of Greenland and Antarctica derived from CryoSat2, The Cryosphere, 8, 1539-1559, https://doi.org/10.5194/tc-81539-2014, 2014.

Lilien, D., Steinhage, D., Taylor, D., Yan, J.-B., O’Neill, C., Miller, H., Gogineni, P., Dahl-Jensen, D., and Eisen, O.: VHF Radio Echo Sounding from Dome C to Little Dome C, Zenodo [data set], https://doi.org/10.5281/zenodo.4687049, 2021.
Lliboutry, L.: A critical review of analytical approximate solutions for steady state velocities and temperatures in cold ice-sheets, $\mathrm{Z}$. Gletscherkd. Glazialgeol., 15, 135-148, 1979.

Morlighem, M., Rignot, E., Binder, T., Blankenship, D. D., Drews, R., Eagles, G., Eisen, O. Ferraccioli, F., Forsberg, R., Fretwell, P., Goel, V., Greenbaum, J. S., Gudmundsson, H., Guo, J., Helm, V., Hofstede, C., Howat, I., Humbert, A., Jokat, I., Karlsson, N.B., Lee, W., Matsuoka, K., Millan, R., Mouginot, J., Paden, J., Pattyn, F., Roberts, J. L., Rosier, S., Ruppel, A., Seroussi, H., Smith, E. C., Steinhage, D., Sun, B., van den Broeke, M. R., van Ommen, T., van Wessem, M., and Young, D. A.: Deep glacial troughs and stabilizing ridges unveiled beneath the margins of the Antarctic ice sheet, Nat. Geosci., 13, 132-137, https://doi.org/10.1038/s41561-019-0510-8, 2020.

Parrenin, F., Hindmarsh, R., and Rémy, F.: Analytical solutions for the effect of topography, accumulation rate and lateral flow divergence on isochrone layer geometry, J. Glaciol., 52, 191-202, https://doi.org/10.3189/172756506781828728, 2006.

Parrenin, F., Barnola, J.-M., Beer, J., Blunier, T., Castellano, E., Chappellaz, J., Dreyfus, G., Fischer, H., Fujita, S., Jouzel, J., Kawamura, K., Lemieux-Dudon, B., Loulergue, L., MassonDelmotte, V., Narcisi, B., Petit, J.-R., Raisbeck, G., Raynaud, D., Ruth, U., Schwander, J., Severi, M., Spahni, R., Steffensen, J. P., Svensson, A., Udisti, R., Waelbroeck, C., and Wolff, E.: The EDC3 chronology for the EPICA Dome C ice core, Clim. Past, 3, 485-497, https://doi.org/10.5194/cp-3-485-2007, 2007.

Parrenin, F., Cavitte, M. G. P., Blankenship, D. D., Chappellaz, J., Fischer, H., Gagliardini, O., Masson-Delmotte, V., Passalacqua, O., Ritz, C., Roberts, J., Siegert, M. J., and Young, D. A.: Is there 1.5-million-year-old ice near Dome C, Antarctica?, The Cryosphere, 11, 2427-2437, https://doi.org/10.5194/tc-11-24272017, 2017.

Passalacqua, O., Ritz, C., Parrenin, F., Urbini, S., and Frezzotti, M.: Geothermal flux and basal melt rate in the Dome $\mathrm{C}$ region inferred from radar reflectivity and heat modelling, The Cryosphere, 11, 2231-2246, https://doi.org/10.5194/tc-11-22312017, 2017.

Passalacqua, O., Cavitte, M., Gagliardini, O., Gillet-Chaulet, F., Parrenin, F., Ritz, C., and Young, D.: Brief communication: Candidate sites of $1.5 \mathrm{Myr}$ old ice $37 \mathrm{~km}$ southwest of the Dome C summit, East Antarctica, The Cryosphere, 12, 2167-2174, https://doi.org/10.5194/tc-12-2167-2018, 2018.

Salvatier, J., Wiecki, T. V., and Fonnesbeck, C.: Probabilistic programming in Python using PyMC3, PeerJ Comput. Sci., 2, e55, https://doi.org/10.7717/peerj-cs.55, 2016.

Tison, J.-L., de Angelis, M., Littot, G., Wolff, E., Fischer, H., Hansson, M., Bigler, M., Udisti, R., Wegner, A., Jouzel, J., Stenni, B., Johnsen, S., Masson-Delmotte, V., Landais, A., Lipenkov, V., Loulergue, L., Barnola, J.-M., Petit, J.-R., Delmonte, B., Dreyfus, G., Dahl-Jensen, D., Durand, G., Bereiter, B., Schilt, A., Spahni, R., Pol, K., Lorrain, R., Souchez, R., and Samyn, D.: Retrieving the paleoclimatic signal from the deeper part of the EPICA Dome C ice core, The Cryosphere, 9, 1633-1648, https://doi.org/10.5194/tc-9-1633-2015, 2015.

Van Liefferinge, B. and Pattyn, F.: Using ice-flow models to evaluate potential sites of million year-old ice in Antarctica, Clim. Past, 9, 2335-2345, https://doi.org/10.5194/cp-9-23352013, 2013. 
Van Liefferinge, B., Pattyn, F., Cavitte, M. G. P., Karlsson, N. B., Young, D. A., Sutter, J., and Eisen, O.: Promising Oldest Ice sites in East Antarctica based on thermodynamical modelling, The Cryosphere, 12, 2773-2787, https://doi.org/10.5194/tc-122773-2018, 2018.

Winter, A., Steinhage, D., Arnold, E. J., Blankenship, D. D., Cavitte, M. G. P., Corr, H. F. J., Paden, J. D., Urbini, S., Young, D. A., and Eisen, O.: Comparison of measurements from different radio-echo sounding systems and synchronization with the ice core at Dome C, Antarctica, The Cryosphere, 11, 653-668, https://doi.org/10.5194/tc-11-653-2017, 2017.

Yan, J.-B., Li, L., Nunn, J. A., Dahl-Jensen, D., O’Neill, C., Taylor, R. A., Simpson, C. D., Wattal, S., Steinhage, D., Gogineni, P., Miller, H., and Eisen, O.: Multiangle, Frequency, and Polarization Radar Measurement of Ice Sheets, IEEE Journal of Selected Topics in Applied Earth Observations and Remote Sensing, 13, 2070-2080, https://doi.org/10.1109/JSTARS.2020.2991682, 2020 .
Young, D. A., Roberts, J. L., Ritz, C., Frezzotti, M., Quartini, E., Cavitte, M. G. P., Tozer, C. R., Steinhage, D., Urbini, S., Corr, H. F. J., van Ommen, T., and Blankenship, D. D.: High-resolution boundary conditions of an old ice target near Dome C, Antarctica, The Cryosphere, 11, 1897-1911, https://doi.org/10.5194/tc11-1897-2017, 2017. 